Peter Pawlowsky

Wissensmanagement 



\section{Peter Pawlowsky}

Wissens-

management

DE GRUYTER

OLDENBOURG 
ISBN 978-3-11-047492-3

e-ISBN (PDF) 978-3-11-047493-0

e-ISBN (EPUB) 978-3-11-047510-4

Library of Congress Control Number: 2019941258

Bibliografische Information der Deutschen Nationalbibliothek

Die Deutsche Nationalbibliothek verzeichnet diese Publikation in der Deutschen Nationalbibliografie; detaillierte bibliografische Daten sind im Internet über http://dnb.dnb.de abrufbar.

(c) 2019 Walter de Gruyter GmbH, Berlin/Boston

Umschlaggestaltung: ArtRoseStudio/iStock/Getty Images Plus

Satz: le-tex publishing services $\mathrm{GmbH}$, Leipzig

Druck und Bindung: $\mathrm{CPI}$ books $\mathrm{GmbH}$, Leck

www.degruyter.com 